\title{
SocArXiv
}

Preprint :

osf.io/0000

\section{Scale for Attitude towards Water Conservation}

\author{
Archana Reddy ${ }^{1}$ \\ Christelle Lewis ${ }^{1}$ \\ Rakesh Sengupta ${ }^{1}$ \\ ${ }^{1}$ SR Engineering College, Warangal
}

\begin{abstract}
Water Conservation is the need of the hour and attitudes towards conserving the resources is what is sure to become a priority in the coming years. The paper introduces a scale constructed to test the Attitude towards water conservation in India. It contains various sub-scales that include a General Attitude towards water conservation, Past behavior/experience, Moral obligation to save water resources, Perceived water right, and Behavioural intention of conserving water resources. 432 participants participated in a nationwide survey and their responses were checked for reliability. Results reveal that people generally have a positive attitude towards water conservation and that there is substantial potential of the resources' conservation.
\end{abstract}

Keywords: Water Conservation, Attitudes, Attitude Scale, Perceived water right, Moral Obligation to save water.

\section{Introduction}

Over the next few years, numerous river basins across the world are likely to experience water scarcity Gain and Giupponi (2015). Groundwater, the primary source of freshwater in the world is being used at a faster rate than it gets replenished Chaudhary et al. (1996) The scarcity is a result of not just the demand of limited water resources, but also the flawed planning, management, economic policies, and other social factors. The failure to plan and conserve a natural resource is due to the lack of awareness of the need to conserve the resource or the public's lack of acknowledging the moral obligation to conserve water Gain and Giupponi (2015).

Compared to other natural phenomenons like meteorological effects, over withdrawal of groundwater due to urbanization; especially in cities, is the major factor in the depletion of groundwater resources Gautam et al. (2017) . Various cities in India currently suffer from water shortage. Most middle-class residents of Delhi- the richest city in India, do not have a dependable access to clean water sources. India has been warned by the World Bank to be on the brink of a severe water crisis. The reports indicate that the groundwater is disappearing 
and the rivers are turning into makeshift sewers.

The situation has been too grave for just the Central Ground Water Authority Sarkar (2010) to regulate groundwater development. Since aquifers have no boundaries akin to political boundaries, a state (and a country's) inappropriate management of its resources is to have a severe impact on the neighbouring states and countries Rodell et al. (2009) . This may cause more political problems between states and/or countries. Despite the gravity of the situation, there is no immediate action being taken to make water conservation a priority; this is because people are still doing the same thing they did thousands of years ago, their consumption of water resources have only multiplied due to the adoption of the modernistic lifestyle.

An important component of water management is to reduce the demand through water conservation ? The only remedy to avert the crisis is to create new technologies for reusing water and encouraging people to conserve water. A positive attitude towards water conservation could be the first step in what might be a long journey ahead to solve India's water crisis. Although the leap is small, it's a good place to start. At the rate of how much India is modernising, an individual stance to conserve water in a day to day life will only be good on the conscience but also make people responsible citizens. Awareness about water conservation is therefore important for more people to support the active implementation of water conservation. Various studies have been conducted by water authorities across India, government departments, and independent and academic research work. Despite these studies, little is known about India's attitude towards conservation and engaging in the same particularly over the past decade. In order to understand what could influence the change in attitude and thereby bring about a change of behaviour, we shift our attention from understanding water crisis to understanding the existing attitude of the society towards water crisis.

Ajzen's theory of planned behaviour Ajzen et al. (1991) proposes that intentions are the cognitive means to direct our beliefs and perception towards an intent to act, and further towards taking action. Intentions are further deemed to be influenced by our attitudes and, our attitudes change amongst many others with the subjective norm (to engage in a behaviour because we see it as a socially expected behaviour) and perceived behavioural control (to perceive the behaviour as something that we can engage in) Nigbur et al. (2010). We address the current attitude towards water conservation by providing baseline data about Indians' attitudes and behavior/behavioural intentions in conserving water. The data further aided in the developing and standardising of a tool to quantify the attitude towards water conservation

. Since the tool is derived from the Ajzen's theory of Planned Behavior, it would help predict the attitude towards water conservation.//

\subsection{Scale}

The Attitude scale for water conservation construes 5 primary sub-scales, namely:

- General Attitude towards water conservation

- Past behavior

- Moral obligation to save water resources

- Behavioural intention of conserving water resources

- Nuanced Analysis of Water Resource

The purpose of the study is to understand and construct an attitude scale in acknowledgment of the fact that attitudes influence behavioural intentions as well as behavior and therefore, represents a crucial antecedent construct that agents of persuasion target. 
It also consists of two other questions from two scales that acts as grouping variables or moderators of attitude. The two secondary sub-scales are:

- Perceived water right

- Past Experience

\begin{tabular}{|c|c|c|}
\hline Scale & Item no. & Question/ Statement \\
\hline \multirow{11}{*}{ GAWC } & 1 & More attention to water conservation is needed \\
\hline & 3 & I am very positive about water conservation \\
\hline & 4 & I could make more effort to conserve water \\
\hline & $8^{*}$ & I feel no pressure to conserve water at the moment \\
\hline & $9^{*}$ & Water Shortage issues don’t affect me. \\
\hline & $10^{*}$ & I am not concerned at all with water conservation \\
\hline & $11^{*}$ & Water conservation isn't my responsibility. \\
\hline & $12^{*}$ & It is challenge to convince others to conserve water \\
\hline & $13^{*}$ & The need for water conservation depends on location \\
\hline & 19 & Water conservation is important \\
\hline & 20 & Water conservation is necessary because of water scarcity \\
\hline \multirow[t]{2}{*}{$\mathrm{PB}$} & 2 & I conserve water whenever I can \\
\hline & 5 & I advocate water conservation among my friends and family \\
\hline $\mathrm{PE}$ & 6 & I have experienced limited water supply before. \\
\hline NAWR & & Water conservation alone can solve India's water problem \\
\hline \multirow[t]{2}{*}{ PMO } & 14 & Water conservation alone can solve India's water problem \\
\hline & 15 & Everybody should save water because water resources are limited \\
\hline PWR & 16 & $\begin{array}{l}\text { Everybody has the right to use water according to his/her own interest, } \\
\text { and the government should satisfy everyone's demand. }\end{array}$ \\
\hline \multirow[t]{2}{*}{$\mathrm{BI}$} & 17 & $\begin{array}{l}\text { If circumstances allowed you, would you like to } \\
\text { reduce water consumption at home? }\end{array}$ \\
\hline & 18 & $\begin{array}{l}\text { If circumstances allowed you, would you like to change } \\
\text { or install some water-saving appliances? }\end{array}$ \\
\hline
\end{tabular}

Table 1: Attitude Scale for Water Conservation containing 5 primary Sub-scales i.e., The General Attitude towards water conservation (GAWC), Past Behavior (PE), Perceived Moral Obligation (PMO), , Behavioral Intentions (BI), and Nuanced analysis of water resources(NAWR) as well as the 2 secondary sub-scales Perceived Water Rights (PWR) and Past Experience(PE). Items marked with an asterisk were negatively scored(revered scoring)

\section{Methodology}

\subsection{Questionnaire Construction}

We made a data base on previous water conservation and those scales and questions that were not relevant to the purpose of the study were filtered out. Some questions were improvised so as to fit the purpose of the study as well as the choice of sample.

Finally, A 20 item questionnaire with 5 sub-scales were constructed to check the attitude towards water conservation in India. 


\subsection{Sub-Scales}

1. The General Attitude towards water conservation (GAWC):The 11 items under this factor tapped awareness of people towards water scarcity and their perceived scope towards the increasing need to conserve water. The questions were adopted from Australians' Water Conservation Behaviours and Attitudes citedolnicar2010australians. Their questions were derived from insights based on a qualitative study they previously did. The items in the scale included questions or statements about the general attitude towards water conservation For example, "More attention to water conservation is needed.", "Water Storage issues don't affect me.", "The need for water conservation depends on location." and so forth.

2. Past Experience (PE): The 3 items in this sub-scale emphasises upon the participant's prior encounter with water shortage and the efforts they have/have not put into conserving water; i.e., variable factors that may or may not affect the attitude to conserve water. For example: "I conserve water wherever I can.", " I advocate water conservation.", etc.

3. Perceived Moral Obligation (PMO): Behavior could often be influenced by moral ethics. This could further extend to why we engage in certain social acts. The items of PMO measures the extent to which one feels obligated to conserve water. For instance, the 2 items are "Water is a natural resource, everybody is obligated to treasure it.", "Everybody should save water because water resources are limited."

4. Behavioral Intentions (BI): The items in this factor measure the extent to which one's attitude reflects in their actions. The questions being, "If circumstances allowed you, would you like to reduce water consumption at home?", "If circumstances allowed you, would you like to change or install some water-saving appliances." 5. Nuanced Analysis of Water Resource(NAWR): The item in this scale is an ambiguous question; a subtle portal that would tell us if the person's attitude towards water conservation is limited to just conserving water or if they think that other factors affect the Water problems we face in India. for eg,. afforestation, Reusing water etc. The statement states that conserving water alone can save India's water problem. If the participant strongly agrees to this, then the attitude towards water conservation is only superficial. The Sub-scale NAWR should be seen alongside the GAWC scale to interpret results. Other one item scales that were included for qualitative purposes. 1. Past Experiences (PE): The scale contains a single item that asks for an extend to which the respondent has experienced a limited water supply in the past.

2. Perceived Water Rights (PWR): Depending on one's opinion on what their right towards the natural resources is, their attitude towards its depletion could vary. PWR Lam (1999) measures the extent to which people think of access to water as their basic right. For example "Everybody has the right to use water according to his/her own interest, and the government should satisfy everyone's demand."

The questions across the sub-scales are listed in Table 1

\subsection{Scoring}

A 5-Point Likert Scale was used to collect responses for each question. The scale ranged from Strongly Agree to Strongly Disagree. For the complete questionnaire, see Appendix A. The items had been segregated for positive scoring (Items: $1,2,3,4,5,6,7,14,15,16,17,18,19,20$ ) and negative scoring (Items: 8,9,10,11,12,13). For Positively scored questions, Strongly agree received a score of 5, Agree received a score of 4 and so on. For Negatively scored questions, the scoring was reversed; Strongly agree received a score of 1, agree received a score of 2 and 
so on.

The scores were carefully selected so as to attribute high scores to a positive attitude towards water conservation. For example, in Question 1, Strongly agreeing to the statement "More attention to water conservation is needed" indicates a positive attitude towards water conservation hence Strongly agree is scores as 5 . Whereas, in Question 10, Strongly agreeing to the statement "I am not concerned at all with water conservation" does not indicate a positive attitude towards water conservation. Therefore, for a negatively scored statement, a reverse scoring is observed where Strongly agree is given a score of 1 , agree is given a score of 2 and so forth.

\subsection{Range of Scores}

For positive and negative scoring (after reverse scoring), a maximum score is obtained by the choice that scored 5 for all the questions/items whereas, a minimum score is obtained by the choice of 1 for all the questions/ items.

The sub-scale GAWC/ General attitude towards water conservation has 11 items Score ranges from a maximum of 55 to a minimum of 5. The sub-scale PBI/ Past Behavior or Experience has 3 items therefore the maximum score an individual can obtain is 15 and the minimum score is 3. The sub-scale PMO/ Perceived moral obligation to conserve water has two items therefore the the maximum and minimum score an individual can obtain from this sub-scale is 5 and 2 respectively. The sub-scale PWR/ Perceived Water Right has only a single question thus the range of score is in between 5 and 1. Sub-scale BI/ Behavioural Intentions has 2 items therefore the maximum and minimum score will be 10 and 2 respectively.

5 primary sub-cales (GAWC, PB,PMO, BI, NAWR) are added to obtain the total score of the attitude scale. The maximum score an individual can score is 90 and the minimum is 18 .

\subsection{Data Collection}

We collected 432 responses from participants all over the country. Survey Monkey -a data collection app \& website, was used to collect participants' responses on the questionnaire in the English Language. Web links, QR codes, and Social Networking templates helped the participants access the survey used to collect responses. We analysed the collected responses on SPSS.

\section{Results}

We analysed the data for Cronbach's alpha. Each of the sub-scales were tested for internal consistency. Select questions from the questionnaire were grouped under the Past Experience factor considering that the nature of the questions was not inclined towards capturing the change in attitude, but carried information important enough to contribute towards a change. The value for General Attitude towards water conservation and Perceived moral obligation seem to fall in close questionable range with 0.684 and 0.670 respectively. Behavioural Intentions sub-scale carries greater and acceptable value of 0.725 .

We analysed reliability of scales that contained more than one item. Table 2 shows the results 


\begin{tabular}{|c|c|c|c|c|c|c|c|c|c|}
\hline \multirow[t]{5}{*}{ Sub-scale } & \multirow[t]{5}{*}{$\mathrm{N}$} & \multirow[t]{5}{*}{ M } & \multirow[t]{5}{*}{ SD } & \multicolumn{6}{|c|}{ Reliability } \\
\hline & & & & \multirow[t]{4}{*}{ Cronbach's $\alpha$} & \multicolumn{5}{|c|}{ Split-Half Reliability } \\
\hline & & & & & \multirow{3}{*}{ Gullman's COF } & \multicolumn{4}{|c|}{ Cronbach's $\alpha$} \\
\hline & & & & & & \multicolumn{2}{|c|}{$1^{\text {st }}$ half } & \multicolumn{2}{|c|}{$2^{\text {nd }}$ half } \\
\hline & & & & & & $\alpha$ & $\mathrm{N}$ & $\alpha$ & $\mathrm{N}$ \\
\hline GAWC & 11 & 38.84 & 5.47 & .684 & .738 & 0.53 & 6 & .59 & 5 \\
\hline PMO & 2 & 8.98 & 1.16 & .670 & - & - & - & - & - \\
\hline BI & 2 & 8.60 & 1.26 & .725 & - & - & - & - & - \\
\hline
\end{tabular}

Table 2: Mean (M), Standard Deviation(SD), and Reliability; Chronbach's $\alpha$ and Split-half reliability (Guttman's split-half coefficient), of Primary Sub-scales: General Attitude towards water conservation (GAWC), Perceived Moral Obligation to Conserve Water (PMO), and Behavioural Intentions (BI). Here, $\mathrm{N}$ denotes the number of items analysed. The first half of GAWC consists of: Item $1,3,4,8,9, \& 10 \&$ its second half consists of Item 11,12,13,19,20

for the internal consistency of three scales ie, General Attitude towards water conservation (GAWC), Perceived Moral Obligation to Conserve Water (PMO) and Behavioural Intentions (BI) analysed by Cronbach's alpha. GAWC has an internal consistency with a cronbach's alpha coefficient of 0.684 and a Gullmans's split half reliability of 0.738 . The scale for perceived moral obligation has 2 items with an internal consistency of 0.670 . The scale for behavioural intention has 2 items with an internal consistency of 0.725 .

The frequency of responses of is shown in table A1 of the Appendix. Each question received different responses from different participants. Figure 1A shows the frequency percentage of responses for each attitude choice against each question/item. Please check Appendix Tables A1 and A2 for the same. Table A2 shows the frequency percentage of responses that was derived based on data shown in Table A1.

There was an overall above average positive attitude towards water conservation with a mean score of $70.86(\mathrm{SD}=5.7)$ out of a total of 90 which amounts to a $78.73 \%$ inclination rate per participant. Figure 1B illustrates a frequency percentage of the samples' attitude towards water conservation. These scores are of that concerning only the primary sub-scales.
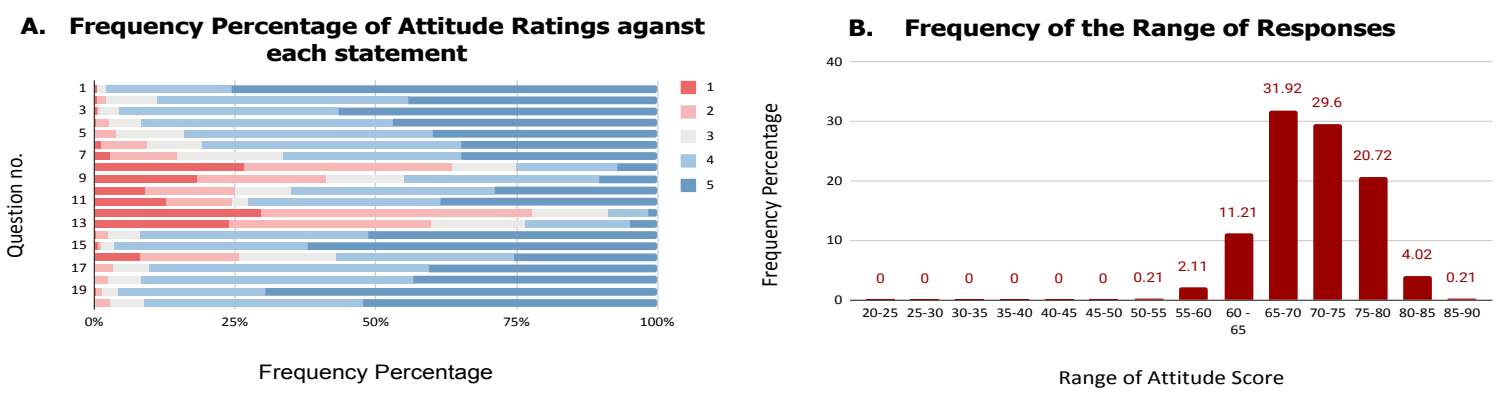

Figure 1A: Frequency Percentage of Responses for all items in the Attitude Towards Water Conservation Scale (ATWC). This data is includive of the primary and the secondary sclaes The legends represent the scores (after reverse scoring) given for the responses.

Figure 1B: Frequency percentage of the range of responses of the entire sample. Miminmum and the maximum score that can be obtained is 18 and 90 respectively. 


\begin{tabular}{|c|c|c|c|c|c|c|c|c|c|}
\hline Table 4a & Item2 & Item5 & Item6 & NAWR & Table 4b & Item2 & Item5 & Item6 & NAWR \\
\hline \hline GAWC & -0.02 & -0.05 & -0.09 & $0.14^{* *}$ & Item2 & 1 & & & \\
& $\mathrm{P}=0.68$ & $\mathrm{P}=0.31$ & $\mathrm{P}=0.08$ & $\mathrm{P}=0.00$ & & & & & \\
\hline PMO & $0.14^{* *}$ & $0.22^{* *}$ & $0.14^{* *}$ & $-0.12^{*}$ & Item5 & $0.39^{* *}$ & 1 & & \\
& $\mathrm{P}=0.00$ & $\mathrm{P}=0.00$ & $\mathrm{P}=0.00$ & $\mathrm{P}=0.01$ & & $\mathrm{P}=0.00$ & & & \\
\hline PWR & 0.05 & 0.07 & $0.12^{*}$ & $-0.19^{* *}$ & Item6 & $0.21^{* *}$ & $0.23^{* *}$ & 1 & \\
& $\mathrm{P}=0.29$ & $\mathrm{P}=0.17$ & $\mathrm{P}=0.02$ & $\mathrm{P}=0.00$ & & $\mathrm{P}=0.00$ & $\mathrm{P}=0.00$ & & \\
\hline BI & $0.17^{* *}$ & $0.27^{* *}$ & $0.18^{* *}$ & $-0.11^{*}$ & NAWR & $-0.27^{* *}$ & $-0.29^{* *}$ & $-0.19^{* *}$ & 1 \\
& $\mathrm{P}=0.00$ & $\mathrm{P}=0.00$ & $\mathrm{P}=0.00$ & $\mathrm{P}=0.03$ & & $\mathrm{P}=0.00$ & $\mathrm{P}=0.00$ & $\mathrm{P}=0.00$ & \\
\hline
\end{tabular}

** Significance at level $0.01(2$ tailed $)$

* Significance at level 0.05(2 tailed)

Table 3: a)Pearson's pairwise correlation of sub-scales GAWC, PMO, PWR, and BI with subscale PB/E (Item2: I conserve water whenever possible. Item5: I advocate water conservation among friends and family Item6: I have experienced limited water supply before) and NAWR (Water conservation alone can solve India's water problem) b) Pearson's pairwise correlation between PB/ E (Item 2,5 \& 6) and NAWR

The frequency of responses of is shown in table A1. Each question received different responses from different participants. Figure 1 shows the frequency percentage of responses for each attitude choice against each question. Please check Table A1 and A2 for the same. Table A2 shows the frequency percentage of responses that was derived based on data shown in Table A1.

Pearson's pairwise correlation was conducted between the scales; results of which indicate that there was a significant positive association between General attitude towards water conservation and Perceived Moral obligation to save water. $(\mathrm{r}(430)=.11, \mathrm{p}<.05)$. Significant positive association was also observed between General attitude towards water conservation and Behavioral intentions to conserve water $(\mathrm{r}(430)=.16, \mathrm{P}<.01)$. General attitude towards water conservation was negatively correlated with the Perceived Water Rights $(\mathrm{r}(430)=-0.78$, $\mathrm{P}<.01$ ).

There is no correlation between Perceived water rights and Perceived moral obligation to conserve water; Nor is any correlation observed between Perceived water right and Behavioural Intention.

A significant positive association is observed between Behavioural Intention and Perceived moral obligation $(\mathrm{r}(430)=.48, \mathrm{P}<.01)$.

Pearson's pairwise correlation was conducted between the scales; results of which indicate that there was a significant positive association between General attitude towards water conservation and Perceived Moral obligation to save water. $(\mathrm{r}(430)=.11, \mathrm{p}<.05)$. Significant positive association was also observed between General attitude towards water conservation and Behavioral intentions to conserve water $(\mathrm{r}(430)=.16, \mathrm{P}<.01)$. General attitude towards water conservation was negatively correlated with the Perceived Water Rights $(\mathrm{r}(430)=-0.78$, $\mathrm{P}<.01$ ). There is no correlation between Perceived water rights and Perceived moral obligation to conserve water. Nor is any correlation observed between Perceived water right and Behavioural Intention.

A significant positive association is observed between Behavioural Intention and Perceived 
moral obligation $(\mathrm{r}(430)=.48, \mathrm{P}<.01)$.

Results of Pearson's 2 tailed pairwise correlation indicates that there was a significant positive association between the conservation of water (Item 2) and advocating others to conserve water (Item 5) $(\mathrm{r}(430)=.39, \mathrm{P}<.01)$, conservation of water (Item 2) and experiences of limited water supply in the past (Item 6$)(\mathrm{r}(430)=.21, \mathrm{P}<.01)$, advocating water conservation(Item $5)$ and experiences of limited water supply in the past (Item 6) $(\mathrm{r}(430)=.23, \mathrm{P}<.01)$.

Pearson's pairwise correlation of Item 2,5, and 6 all showed negative association with the statement on Nuanced Analysis of Water Resource. I.e., There is a negative association with the belief that Water conservation alone can solve India's water problems( NAWR statement) with practice in conserving water (Item 2$)(\mathrm{r}(430)=-.27, \mathrm{P}<.01)$, advocated water conservation $($ Item 5$)(\mathrm{r}(430)=-.29, \mathrm{P}<.01)$ and experiences with limited water supply in the past $(\mathrm{r}(430)=-.19, \mathrm{P}<.01)$.

\section{Discussion}

Water- a natural resource is considered as being bountiful. In real time, the general public finds it hard to acknowledge that they are in the $11^{\text {th }}$ hour before a severe water crisis. Rawl's, in his Text 'A Theory of Justice' argues that capitalist institutions must define and protect primary goods such as natural resources as higher order goods. It is the very foundation stone that all other of man's deliberate needs are satisfied, whatever that may be. Primary goods are of the highest interest or need for what a rational man requires Rawls (1971). Their existence revolves around it although it attributes no market price onto itself; yet. With more of the primary goods being available, success is assured in carrying out man's intentions and advancements, whatsoever it may be Rawls (1980) Water is one such higher order good, the value of which people need to acknowledge. A society that is primarily concerned with decision useful information can neglect to account for the importance of these goods even when it's on the verge of the crisis Rawls (1980).

To fix a problem, it is important to know how severe it is. Knowing the extent to which people are aware of the problem provides the foremost step; For, something as important as water conservation needs a collecting effort. Determining people's motives towards saving water is important in designing educational urban water saving strategies, hence understanding attitude and behaviour towards consumption towards the resource is vital to its conservationRawls (1980).

It has been previously established that the attitudes and beliefs of consumers directly impact on water use behaviours which are closely linked to water demand Willis et al. (2011). To assess the relationship between general and specific environmental beliefs and their effects on pro-environmental behavior, an attitude scale was developed. Results seem to indicate that most people the water conservation scales are reliable and valid. Reliability was assessed by Cronbach's alpha, and split half method as well as comparing the reliability scored to scores of the that of the original scale from which the questions were derived from producing adequate values in every case.

The 20 item questionnaire has 5 scales. The reliability of 4 scales were analysed for all 20 questions answered by 432 participants. The cronbach's coefficient assessing the internal consistency of the Scale General Attitude towards water conservation (GAWC) is 0.684 and the Gullmans's split half reliability of 0.738 ; both these coefficient scores attest to a considerably good reliability scale in the Indian population. 
The reason for an average score could be due to an anchoring effect caused by varied experiences with the domestic water usage and societal pressures different people across different states in India experience.

The study shows that people who have a moral obligation to conserve water, exhibit a positive attitude towards water conservation that reflects further into a behavioral intention to conserve water resources. The limited supply/ shortage of water conservation they may have experienced in the past could have instilled a positive attitude towards water conservation as well as a moral obligation to conserve water. Experiencing limited water supply has also led to a behavioural intention to conserve water.

People who do have a strong positive attitude towards water conservation, perceive a moral obligation to conserve water, or who has experienced limited water supply in the past, do not believe that water conservation alone can solve India's water problems. Either they are aware of other the circumstances that cause water shortage or they are responsible citizens with a high moral conduct that sees conservation of water as relative to other problems.

People who strongly believe that they have the right to use water would feel less obligated to save water. Hence, we had expected the the moral obligation to be negatively correlated to the perceived water right. However, 99 we found no such results from our sample.

People who have a general positive attitude towards water conservation believe that they are entitled to the water resources. These results are contradictory to the majority of results about the nuanced analysis of water conservation where there is a negative correlation between the belief that water conservation alone can solve India's water problems, and advocating water conservation among others, a behavioural intention and a perceived moral obligation to conserve water. Thus, in totality, a nuanced analysis could tell us more about how positive peoples' attitude towards water conservation are.

There is also a positive correlation between experiences of water shortage in the past and perceived water right. This could only tell us that their water shortage situation was perceived as an unjust reason that caused their water shortage; political or otherwise.

The scale is suitable to tap the attitude towards water conservation by excluding Sub-Scale $\mathrm{PE} /$ Past Experience (experience of water shortage in the past), for it could vary from person to person and place to place. It could better serve as a grouping variable instead. The sub-scale PWR/ Perceived water right had ambiguous correlations that needs to be modeled. Thus, it could act as a moderator instead of an independent variable. Exclusion of the score from this scale should also be observed when considering the attitude score.

\section{Conclusion}

Majority of the people show an above average positive attitude towards water conservation that can be tapped with the standardized Attitude scale for water conservation that contains 6 sub-scales all of which has a reliability within the range of 6.5- 7.5 reliability coefficient.

There are positive associations between the general attitude towards water conservation, perceived moral obligation to conserve water and a behavioural intention of the same. Thus, these variables determine the quality of the attitude. The NAWR should be considered along side the GASWC, PMO, \& BI to determine the depth of their analysis. The sum of the five primary sub-scales (NAWR, GASWC, PMO, BI \& PB) would determine each individual's attitude score. The scale PWR and PE(secondary sub-scales) can be included along with the questionnaire for qualitative purposes. 


\section{Acknowledgment}

We thank the Department of Science and Technology for funding the project of which this was a mandatory part of. We thank Dr. Rajashekar P. V. For his dedication in seeing though the completion of the project. We sincerely than Ms. Madhira Aswini, Ms. Nagaveli Sushma and Ms. Soumya Madham for their constant support and assistance in sorting the data and giving valuable feedback whenever necessary.

\section{References}

Ajzen, I. et al. (1991). The theory of planned behavior. Organizational behavior and human decision processes, 50(2):179-211.

Chaudhary, B., Kumar, M., Roy, A., and Ruhal, D. (1996). Applications of remote sensing and geographic information systems in ground water (investigations in sohna block, gurgaon district (india). International Archives of Photogrammetry and Remote Sensing, 31:18-23.

Gain, A. K. and Giupponi, C. (2015). A dynamic assessment of water scarcity risk in the lower brahmaputra river basin: An integrated approach. Ecological Indicators, 48:120-131.

Gautam, P. K., Arora, S., Kannaujiya, S., Singh, A., Goswami, A., and Champati, P. K. (2017). A comparative appraisal of ground water resources using grace-gps data in highly urbanised regions of uttar pradesh, india. Sustainable Water Resources Management, 3(4):441-449.

Lam, S.-P. (1999). Predicting intentions to conserve water from the theory of planned behavior, perceived moral obligation, and perceived water right 1. Journal of Applied Social Psychology, 29(5):1058-1071.

Nigbur, D., Lyons, E., and Uzzell, D. (2010). Attitudes, norms, identity and environmental behaviour: Using an expanded theory of planned behaviour to predict participation in a kerbside recycling programme. British Journal of Social Psychology, 49(2):259-284.

Rawls, J. (1971). A theory of justice.,(oxford university press: Oxford, uk.).

Rawls, J. (1980). Kantian constructivism in moral theory. The journal of philosophy, $77(9): 515-572$.

Rodell, M., Velicogna, I., and Famiglietti, J. S. (2009). Satellite-based estimates of groundwater depletion in india. Nature, 460(7258):999-1002.

Sarkar, B. (2010). A gis approach to morphometric analysis of damodar river basin and groundwater potentiality mapping in jharia coalfield. Silver Jubilee Publication-II, $25(3 \& 4): 1$.

Willis, R. M., Stewart, R. A., Panuwatwanich, K., Williams, P. R., and Hollingsworth, A. L. (2011). Quantifying the influence of environmental and water conservation attitudes on 
household end use water consumption. Journal of environmental management, 92(8):19962009 .

\section{Appendix}

\begin{tabular}{|c|c|c|c|c|c|c|c|c|c|c|c|}
\hline Table A1 & \multicolumn{9}{|c|}{ Response frequency } & Table A2 & \multicolumn{3}{|c|}{ Frequency Percentage of Responses (\%) } \\
\hline Q no. & 1 & 2 & 3 & 4 & 5 & Q no. & 1 & 2 & 3 & 4 & 5 \\
\hline \hline 1 & 2 & 0 & 7 & 96 & 327 & 1 & 0.46 & 0 & 1.62 & 22.22 & 75.69 \\
\hline 2 & 2 & 7 & 39 & 193 & 191 & 2 & 0.46 & 1.62 & 9.03 & 44.68 & 44.21 \\
\hline 3 & 2 & 1 & 16 & 168 & 245 & 3 & 0.46 & 0.23 & 3.70 & 38.89 & 56.71 \\
\hline 4 & 1 & 10 & 25 & 193 & 203 & 4 & 0.23 & 2.31 & 5.79 & 44.68 & 46.99 \\
\hline 5 & 0 & 17 & 52 & 191 & 172 & 5 & 0 & 3.94 & 12.04 & 44.21 & 39.81 \\
\hline 6 & 5 & 36 & 42 & 198 & 151 & 6 & 1.15 & 8.33 & 9.72 & 45.83 & 34.95 \\
\hline $7^{*}$ & 151 & 136 & 81 & 52 & 12 & $7^{*}$ & 2.78 & 12.04 & 18.75 & 31.48 & 34.95 \\
\hline $8^{*}$ & 115 & 160 & 49 & 77 & 31 & $8^{*}$ & 26.62 & 37.04 & 11.34 & 17.82 & 7.18 \\
\hline $9^{*}$ & 79 & 99 & 60 & 149 & 45 & $9^{*}$ & 18.28 & 22.92 & 13.89 & 34.49 & 10.42 \\
\hline $10^{*}$ & 39 & 69 & 43 & 156 & 125 & $10^{*}$ & 9.03 & 15.97 & 9.95 & 36.11 & 28.94 \\
\hline $11^{*}$ & 55 & 50 & 13 & 148 & 166 & $11^{*}$ & 12.73 & 11.57 & 3.01 & 34.26 & 38.43 \\
\hline $12^{*}$ & 128 & 208 & 58 & 31 & 7 & $12^{*}$ & 29.63 & 48.15 & 13.43 & 7.18 & 1.62 \\
\hline $13^{*}$ & 103 & 156 & 72 & 80 & 21 & $13^{*}$ & 23.84 & 36.11 & 16.67 & 18.52 & 4.86 \\
\hline 14 & 1 & 9 & 25 & 175 & 222 & 14 & 0.23 & 2.08 & 5.79 & 40.51 & 51.39 \\
\hline 15 & 2 & 3 & 10 & 149 & 268 & 15 & 0.46 & 0.69 & 2.31 & 34.49 & 62.04 \\
\hline 16 & 35 & 76 & 74 & 137 & 110 & 16 & 8.10 & 17.59 & 17.13 & 31.71 & 25.46 \\
\hline 17 & 0 & 14 & 28 & 215 & 175 & 17 & 0 & 3.24 & 3.48 & 49.77 & 40.51 \\
\hline 18 & 0 & 10 & 26 & 209 & 187 & 18 & 0 & 2.31 & 6.02 & 48.38 & 43.29 \\
\hline 19 & 1 & 5 & 12 & 113 & 301 & 19 & 0.23 & 1.16 & 2.78 & 26.16 & 69.68 \\
\hline 20 & 0 & 12 & 26 & 168 & 226 & 20 & 0 & 2.78 & 6.02 & 38.89 & 52.31 \\
\hline & & & & & & Average & 6.74 & 11.50 & 8.77 & 34.51 & 38.47 \\
\hline
\end{tabular}

Table A1: Response Frequency: The frequency of the fve choices againt each question was estimated after reverse scoring of negatively scored questions. The astric beside the questions denote those questions which was scored in reverse.

Table A2:Frequency Percentage of Responses based on data from Table A1

\section{Affiliation:}

Christelle Lewis

SR Engineering College, Warangal,

Telangana, India

E-mail: christellea23@gmail.com

\section{SocArXiv Preprints}

Preprint 